\title{
Erratum to: Chemoembolization of Neuroendocrine Liver Metastases Using Streptozocin and Tris-acryl Microspheres: Embozar (EMBOsphere + ZAnosaR) Study
}

\author{
Jean-Pierre Pelage ${ }^{1,2} \cdot$ Audrey Fohlen $^{1,2} \cdot$ Emmanuel Mitry $^{3} \cdot$ Christine Lagrange $^{4}$. \\ Alain Beauchet ${ }^{5} \cdot$ Philippe Rougier $^{3}$
}

Published online: 18 January 2017

(C) Springer Science+Business Media New York and the Cardiovascular and Interventional Radiological Society of Europe (CIRSE) 2017

\section{Erratum to: Cardiovasc Intervent Radiol DOI 10.1007/s00270-016-1535-7}

The following corrections need to be made to the published article.

On the second page of the article in the "Methods" section, the sentence immediately above the subheading "Demographics" should read:
Baseline characteristics including age at the time of TACE, location of primary tumor (resected or not), Ki67 tumor index, synchronous or metachronous liver metastases, and previous treatments were recorded.

On the fifth page of the article, the beginning of the sentence in the first full paragraph should read:

After 1-2 sessions of TACE, ....

The online version of the original article can be found under doi: 10 . 1007/s00270-016-1535-7.

Jean-Pierre Pelage

pelage-jp@chu-caen.fr

1 Department of Diagnostic Imaging and Interventional Radiology, Caen University and Medical Center, Avenue Cote de Nacre, 14033 Caen Cedex 9, France

2 CERVOxy, CEA, CNRS, ISTCT - Imagerie et Stratégie Thérapeutiques des Pathologies Cérébrales et Tumorales (M Bernaudin), Université de Basse-Normandie UNICAEN, Caen, France

3 Department of Hepatogastroenterology and Oncology, Hopital Ambroise Pare, 9, Avenue Charles de Gaulle, 92104 Boulogne Cedex, France

4 Department of Radiology, Hopital Ambroise Pare, 9, Avenue Charles de Gaulle, 92104 Boulogne Cedex, France

5 Department of Biostatistics and Public Health, Hopital Ambroise Pare, 9, Avenue Charles de Gaulle, 92104 Boulogne Cedex, France 